This item was submitted to Loughborough's Research Repository by the author.

Items in Figshare are protected by copyright, with all rights reserved, unless otherwise indicated.

\title{
Sustainable design education - considering design for behavioural change
}

PLEASE CITE THE PUBLISHED VERSION

http://www.engsc.ac.uk/journal/index.php/ee/article/view/115/165

\section{PUBLISHER}

(c) Higher Education Academy Engineering Subject Centre, Loughborough University

\section{VERSION}

VoR (Version of Record)

\section{LICENCE}

CC BY-NC-ND 4.0

\section{REPOSITORY RECORD}

Lilley, Debra, and V.A. Lofthouse. 2019. "Sustainable Design Education - Considering Design for Behavioural Change”. figshare. https://hdl.handle.net/2134/9722. 
This item was submitted to Loughborough's Institutional Repository (https://dspace.lboro.ac.uk/) by the author and is made available under the following Creative Commons Licence conditions.

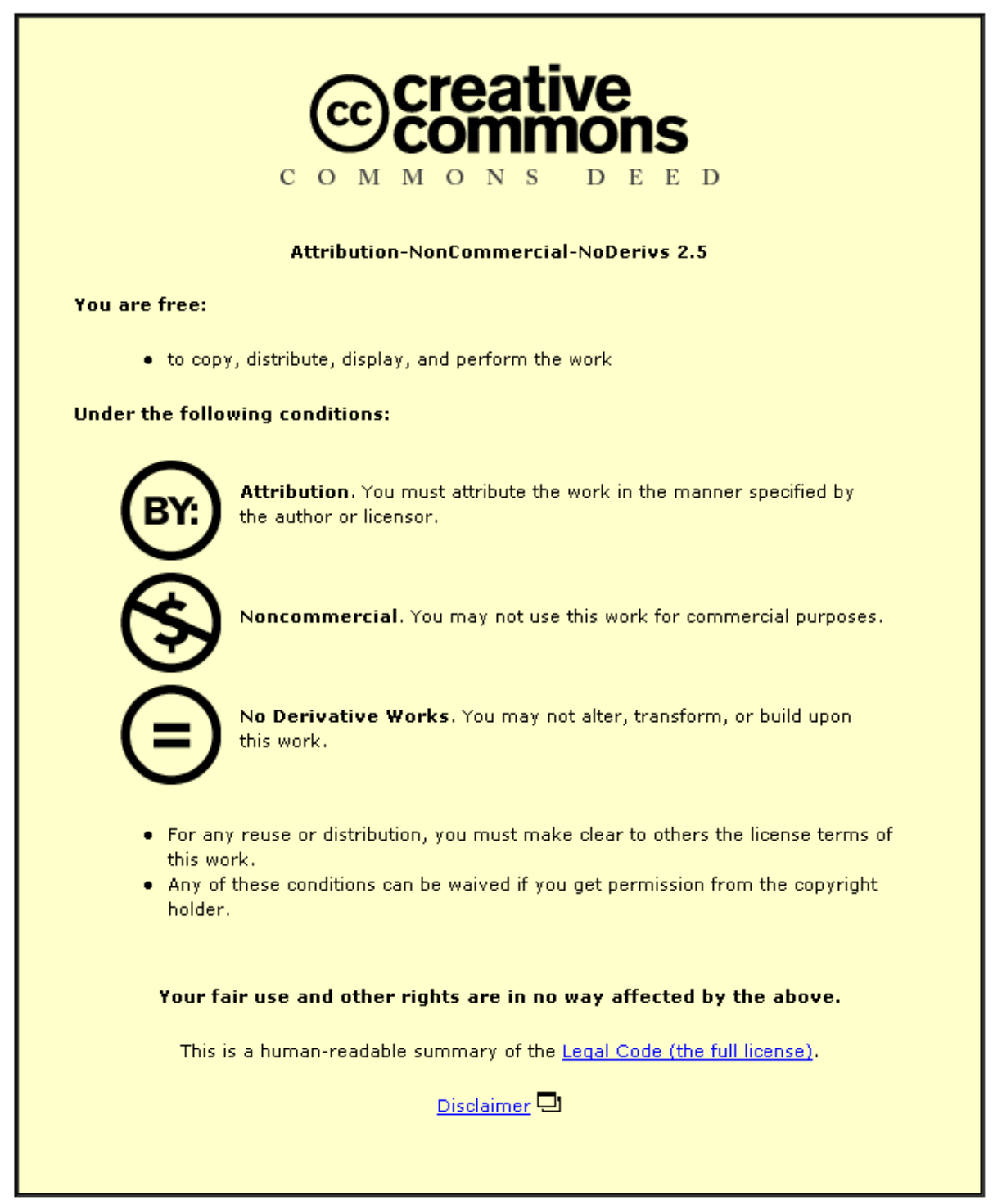

For the full text of this licence, please go to: http://creativecommons.org/licenses/by-nc-nd/2.5/ 


\title{
Sustainable design education - considering design for behavioural change
}

\author{
Debra Lilley and Vicky Lofthouse
}

\begin{abstract}
This paper reports on the development and evaluation of 'design-behaviour' (www.design-behaviour.co.uk), a webbased resource created to support the teaching of Design for Behavioural Change - a new field of enquiry in sustainable design research. The paper presents a brief introduction to sustainable design teaching in the Department of Design and Technology at Loughborough University. It goes on to outline the project methodology used to develop a web-based resource to centralise and disseminate teaching material on the subject of Design for Behavioural Change for a design and engineering audience. Selected findings from a literature review are introduced and the results of a pilot study (through which the authors explored how this subject could be taught to industrial/product design students) are discussed. The paper explains how the resource was developed and presents the results of an evaluative user questionnaire. It concludes with an outline of improvements made in response to feedback received and a discussion of further developments planned.
\end{abstract}

\section{Setting the context}

The project reported on in this paper set out to identify and develop an appropriate mechanism for collating and distributing teaching material on the subject of Design for Behavioural Change for a design and engineering audience. The work was supported and funded by the Higher Education Academy Engineering Subject Centre.

The Department of Design and Technology at Loughborough University has been teaching undergraduate and postgraduate industrial/ product design students sustainable design since 2000 when an education for sustainability programme was developed to further engage second year students with the sustainable design agenda. Sustainable design thinking is now integrated into other parts of degree level teaching within all years. Sustainable design teaching covers sustainable development (which addresses such concepts as resources, social responsibility, systems and services, designer responsibility and business drivers) and design for sustainability, where students generate concepts to meet a variety of sustainable design briefs. Sustainable design is taught to industrial/product design students at Loughborough University using a blend of lectures, seminars and workshops, supported by a range of web-based resources and assessed through a combination of essay, seminar presentation and extended design project. The emergence of Design for Behavioural Change (Bhamra et al., 2008a; Lilley, 2007), a broad field of enquiry exploring how design could influence user behaviour towards a reduction in the environmental and social impacts of use, brought with it the need for new teaching material. The development of this material and its delivery mechanism forms the basis of this paper.

Vicky Lofthouse has been actively involved in the development of several web-based resources used to support teaching and learning in sustainable design (Lofthouse and Bhamra, 2005; Lofthouse and Bhamra, 2004; Lofthouse, 2001b). Through developing these tools she has gained a detailed understanding of the service, content, visual requirement, language and mode of access required to help make ecodesign tools more appropriate to industrial designers (Lofthouse, 2001a). 'Information/Inspiration' (Lofthouse, 2004), for example, is a web-based ecodesign tool used by three years of undergraduate Design and Technology students and Masters students to support their design projects.

The 'Information/Inspiration' project identified that simple guidance, information and education each have an important role to play in the service delivered by ecodesign tools, but that combining these elements provides a more holistic service and greater benefits than those afforded by the individual constituent parts. The provision of information is the key to a successful tool, but only alongside 
guidance and education. Guidance provision ensures that the most relevant information can be identified and found. Education provision has a supportive role and ensures that the designers have the opportunity to build up an understanding of the main principles of ecodesign in a 'hands-on' way (Lofthouse, 2001a). It was recognised that case study examples bring ecodesign information 'alive' by illustrating how it can be applied, and providing specific information helps to make the examples more credible (Lofthouse, 2001a). Tools also need to look as though they have been created for industrial designers. This means displaying information visually rather than in a written format (Lofthouse, 2001a) and using images wherever possible. The content provided in ecodesign tools of this nature needs to be presented in the form of 'nuggets' of information, rather than large quantities of text, and in an appropriate language for industrial designers (avoiding technical/ scientific jargon and an academic framework). The benefit of a web based approach is that these 'nuggets' of information can be hyperlinked to more detailed information in order to support deeper learning as and when required.

Web-based resources such as 'Information/ Inspiration' are not used as stand-alone tools but as an integral part of the teaching-learningassessment strategy combining traditional and e-learning practices, a method often referred to as 'blended learning' (Garrison and Kanuka, 2004). Providing this type of resource to support studio-based learning builds on a tradition of independent study which is encouraged throughout the degree course - ten years of experience in using this type of approach has shown that it is an effective way of supplying students with case studies. It provides the facility to address the needs of the user who seeks understanding having developed their own questions, as well as the user who is looking for quick solutions rather than meaning, addressing both surface and deeper learning requirements. Through the functions afforded by a website, this type of approach allows students to identify and explore links which are particularly relevant to their studies. It also makes the case studies accessible to others beyond taught classes.

\section{Methodology}

The research methodology for this project consisted of several stages of exploratory, qualitative research (see Figure 1).

As illustrated in Figure 1, material gathered from the literature review (see Literature review - design for sustainable behaviour) formed the basis of a pilot study consisting of two consecutive teaching activities carried out with MSc/MA Industrial Design students at Loughborough University. The aims of the pilot were to:

1. Explore and evaluate how best to teach industrial/product design students how to apply Design for Behavioural Change theory in sustainable design.

2. Generate design case studies which showed how the concept had been developed, as well as the final solution.

The students were given a preparatory lecture to introduce three of the product-led intervention approaches discussed in the literature review and a selection of design case studies taken from the literature. They were then tasked with redesigning a given product to address a social or environmental issue originating from user behaviour.
Figure 1.

Project development process
EMPIRICAL RESEARCH

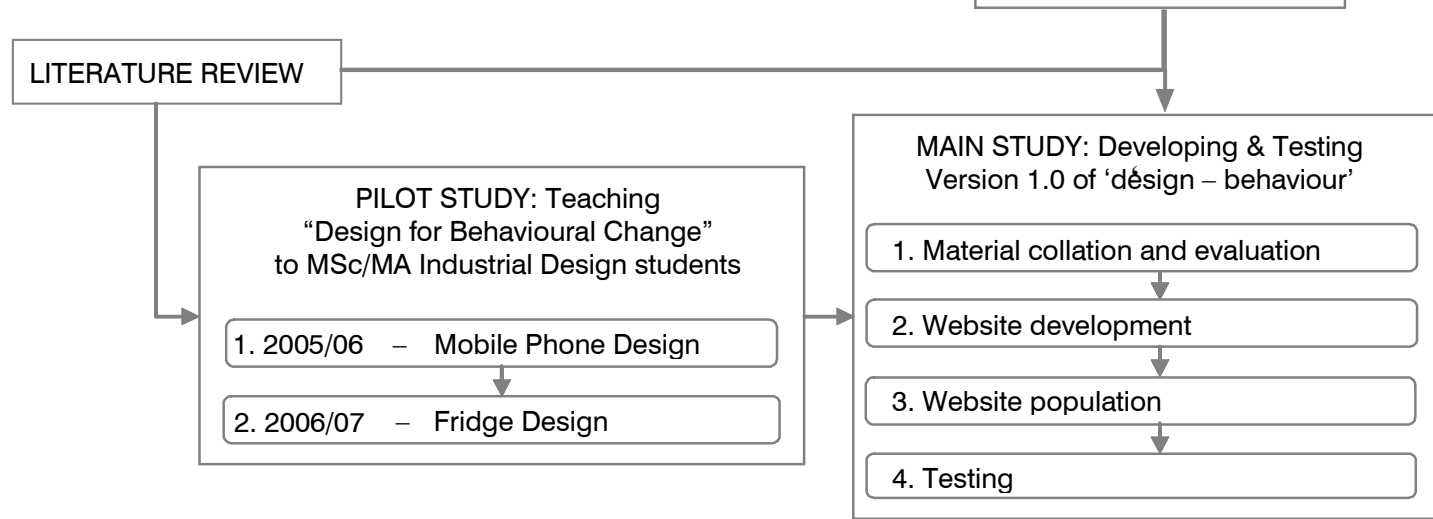


The design brief consisted of three parts:

- Research and development (R\&D). Observing product use and the consequences of user behaviour for society or the environment.

- Redesign. Generating and developing design ideas that could change user behaviour using one of the approaches described in the lecture.

- Final concept. A presentation detailing the final idea and how it could change user behaviour to address one or more of the issues identified in the R\&D stage.

Each student was required to keep a design logbook in which to record their ideas, thoughts and analysis. These were submitted with a copy of their presentation on completion of the project.

The main study consisted of four phases (see Figure 1). The first phase involved reflecting on the material gathered during the literature review, evaluating its appropriateness and gaining an understanding of what kinds of information would be needed to enable practising designers and students to apply this thinking in their design processes. Theory developed through 'Information/Inspiration' (Lofthouse, 2001a) provided a useful basis for the development of the service in terms of visual requirement, language and mode of access for 'design-behaviour'. In order to take a more specific direction on the content, empirical findings which emerged from in-depth face-to-face interviews with eight design and engineering professionals conducted during the main study of Lilley's PhD (2007) were drawn on.

Phase two centred on developing a prototype version of the web-based resource in FrontPage (Version 1.0). FrontPage was selected for its ease of use and the ready availability of the software. Key objectives included identifying potential audiences, identifying their needs (through interviews where possible) and developing the structure for the content.

The third phase of the main study focused on populating the resource by drawing on theoretical findings (Lilley, 2007). Content included design approaches and case studies identified during the literature review, useful websites and blogs and links to further reading.
In phase four, Version 1.0 of 'design-behaviour' was evaluated using a short electronic questionnaire which investigated the content and navigation of the website, general perceptions on its quality, clarity and relevance, areas for improvement and new content for inclusion. The questionnaire was distributed via email to the four MSc/MA Industrial Design students taught in 2006/07 as part of the pilot, the eight design professionals interviewed and 35 members of the Sustainable Design Network who had attended the 'Design I Behaviour' seminar in April 2006. The response rate was $26 \%$. A coding and clustering method was used to analyse the results of the questionnaire and key lessons were drawn out. The authors used this feedback to implement several improvements in an updated version of the resource (Version 1.1) (see Further developments).

\section{Literature review - design for sustainable behaviour} Industrial designers shape the development of products, technologies and services which directly and indirectly impact upon society and the environment (Papanek, 1971) at every stage of the product lifecycle. The application of sustainable design strategies can greatly reduce the environmental and social impacts of these products and services (Lewis et al., 2001). However, as recognised by the forthcoming Directive 2005/32/EC on the ecodesign of Energy-using Products (EuP), the greatest environmental impact of electrical and electronic products often occurs during use and is heavily influenced by consumer behaviour (Rodriguez and Boks, 2005).

In spite of a decade of adverts reminding consumers to adopt more environmentally conscious behaviours and the numerous technological options on offer, most are slow to adopt more sustainable behaviours (DeVries, 2006; Siegle, 2006). Information campaigns such as 'Are you doing your bit?' (DEFRA, 2002) and 'ACT ON CO'' (DEFRA et al., 2008) have failed to create the long term behavioural shift needed to reduce the impact of product use (Scott, 2004; Darby, 2001). The key problem has been that users have to make the link between 'the information', their behaviour and the resulting impact and this makes it difficult to motivate a change in the majority of their behaviour (Bhamra et al., 2008b; Darby, 2001). To encourage behavioural change the causal link between behaviour and positive or 
negative environmental or social consequences must be reinforced (Darby, 2001).

By considering the impact of the use phase, designers have greater potential to reduce environmental and social impacts of the products they create. However, this stage of the lifecycle has historically not been considered in detail. Design for Behavioural Change is a new field of enquiry exploring how design can influence user behaviour. In the context of sustainable design this approach can be applied to reduce negative social and environmental use impacts. Through examining cross-disciplinary literature, Lilley (2007) identified three potential approaches for influencing user behaviour through product design; eco-feedback (McCalley, 2006), behaviour steering (Jelsma and Knot, 2002; Akrich, 1992) and persuasive technology (or captology) (Fogg, 2003). This framework was subsequently refined to include seven approaches which can be applied within design to reduce use impacts (Bhamra et al., 2008a; Bhamra et al., 2008b). Table 1 describes each approach with some examples of their application in product design.

Whilst providing interesting considerations for designers, these approaches have not been widely applied and there is lack of real data on their effectiveness (Bhamra et al., 2008b).

\section{Pilot study}

In 2005/06 Debra Lilley delivered a lecture to MA/MSc Industrial Design students at Loughborough University introducing design for behavioural change. The students were then set a brief which challenged them to apply one of the approaches outlined in the lecture to the design of a mobile phone to reduce the social impacts of its use in public.

An earlier version of the framework shown in Table 1 and a range of product design case studies identified through Lilley's PhD proved extremely useful in explaining the concept of design for behavioural change to the students. However, at that time research in this field was fairly limited in an industrial/product design context and subsequently there were few publications to explain what it was or how to apply it in product design. Existing literature was located across a range of disciplinary areas, making it difficult for designers and engineers to access. Most publications tended to focus on a single approach, were not written from an industrial/product design perspective and contained discipline-specific terminology not readily used or understood in the context of product design. The majority of the existing product design examples identified in the literature, though inspirational, lacked sufficient detail of the designer's research and design processes. This limited their usefulness from an educational perspective as students were unable to understand how the end result was reached. In spite of these limitations, the students taught in 2005/06 engaged with the subject matter and produced a broad range of innovative design concepts in response to the brief (Lilley et al., 2006). One student even went on to study this subject at PhD level.

In 2006/07, the introductory lecture had a different focus: to explore the environmental impacts associated with the use of fridges and develop design solutions to address user behaviour and reduce use impacts (lecture by Debra Lilley and Tang Tang). The students were provided with background contextual information, an overview of design for behavioural change approaches and product case studies illustrating how others had used these approaches to design for sustainable behaviour. By 2007 further research had been undertaken and the body of knowledge on which to draw was greater. The theoretical approaches were more clearly defined and more closely related to sustainable product design. Additionally, a greater range of product design case studies had been identified. A PowerPoint diagram which linked an explanation of each approach with examples of its application in product design was created. Directly linking theory and practice was of great use in engaging the students and furthering their understanding of the subject as it not only enabled them to understand the theory but also 'brought it to life'. From a teaching perspective, being able to 'toggle' between the theory and case study examples through hyperlinked texts embedded in the PowerPoint slides was extremely useful, though limited.

Lilley's experiences of teaching design for behavioural change led the authors to conclude that there was a need for a centralised resource to support teaching and learning in this field. The findings indicated that this resource would need to present clear information about available approaches and provide case studies (detailing research and design processes) to illustrate how these approaches 
Table 1. Design for behavioural change approaches and examples

\section{Eco-information - design oriented education}

Aim: to make consumables visible, understandable and accessible to inspire consumers to reflect upon their use of resources.

\section{How it works:}

1. Product expresses the presence and consumption of resources e.g. water, energy etc.

\section{Examples:}

Power Aware Cord - Seeing Personal Energy Consumption (Interactive Institute, 2004).

2. Product encourages the user to interact with resource use.

Tyranny of the Plug Kitchen Machines - Being involved in powering the product (Van Hoff, 2003).

\section{Eco-choice - design oriented empowerment}

Aim: to encourage consumers to think about their use behaviour and to take responsibility for theirs actions by providing them with options.

\section{How it works:}

Users have a choice and the product enables sustainable use to take place.

Example:

Domestic Energy Display - household system level concept (Design Council, 2005).

\section{Eco-feedback - design oriented links to environmentally or socially responsible action}

Aim: to inform users clearly about what they are doing and to facilitate consumers to make environmentally and socially responsible decisions through offering real-time feedback.

\section{How it works:}

The product provides tangible aural, visual, or tactile signs as reminders to inform users of resource use.

\section{Example:}

Wattson - wireless energy monitor which raises awareness of energy used in the home (DIY Kyoto, 2005)

\section{Eco-spur - design oriented rewarding incentive and penalty}

Aim: to inspire users to explore more sustainable usage through providing rewards to 'prompt' good behaviour or penalties to 'punish' unsustainable usage.

\section{How it works:}

The product shows the user the consequences of their actions through 'rewarding incentives' and 'penalties'.

\section{Example:}

Flower Lamp - Rewarding Energy Behaviours (Interactive Institute, 2004)

\section{Eco-steer - design oriented affordances and constraints}

Aim: to facilitate users to adopt more environmentally or socially desirable use habits through the prescriptions and/or constraints of use embedded in the product design..

\section{How it works:}

The product contains affordances and constraints which encourage users to adopt more sustainable use habits or reform existing unsustainable habits.

\section{Example:}

Unilever Powder Tablet - Counteracting excessive amounts of washing powder consumption by prescribing correct dose (Unilever, 2000).

\section{Eco-technical intervention - design oriented technical intervention}

Aim: to restrain existing use habits and to persuade or control user behaviour automatically by design combined with advanced technology.

\section{How it works:}

The product utilises advanced technology to persuade or control user behaviour automatically.

\section{Example:}

Energy Curtain - Interacting with Daily Light Cycles (Interactive Institute, 2004)

\section{Clever design}

Aim: to automatically act environmentally or socially without raising awareness or changing user behaviour purely through innovative product design.

\section{How it works:}

The design solution decreases environmental impacts without changing the user's behaviour

\section{Example:}

Caroma integrated toilet and washbasin - decreases water use by re-using water for hand-washing to flush toilet (Caroma, 2008) 
could be applied in sustainable design. It was recognised that the increased functionality and flexibility offered by a web-based program would further enhance the delivery of theoretical information and inspirational case studies in a simple, graphic format, enabling lecturers to use it within the classroom and offering a quick and easy path for updating the resource, whilst still being comprehensive enough to facilitate independent study.

The similarity in the characteristics required of this resource with those of 'Information/ Inspiration' led the authors to believe that a blended learning approach would be a suitable way forward for this exploratory piece of work. In response to this need, the authors sought and secured funding to create 'designbehaviour' (www.design-behaviour.co.uk), an educational web-based resource.

\section{Main study: developing the prototype (Version 1.0)}

Over a six month period a prototype version of 'design-behaviour' (Version 1.0) was developed in FrontPage and tested by a cross-section of potential users. The following paragraphs detail the process undertaken to develop the structure, navigation and content of this resource.

\section{Structure and navigation}

As seen in Figure 2, in addition to the homepage (level 1), Version 1.0 of 'designbehaviour' consisted of five main sections (level 2): 'what is it?', 'doing it', 'understanding the user', 'how others have done it' (which held individual webpages (level 3)) and 'about us'.

As illustrated in Figure 3, each webpage featured a vertical menu on the left-hand side with links to the five main sections and homepage. Each level 3 page also featured a horizontal navigation path known as 'breadcrumbs' just below the banner, a mechanism which helps the user to place themselves more easily within the website as well as "shortcut links [...]. to 'jump' to previously viewed pages without using the back button" (Rogers and Chaparro, 2003).

\section{Content}

The findings of the interviews with engineering and design professionals (Lilley, 2007) revealed that resources to support the implementation of design for behavioural change should:

- assist in problem identification

- be explorative, not prescriptive

- be applied in the early 'ideation' stages of the design process

- pose questions, not provide solutions

- inspire designers to solve problems.

Favoured modes for the presentation of information included:

- informal checklists in the form of prompt questions, rather than prescriptive sequential 'steps' to follow

Figure 2.

'Design-behaviour' site map (Version 1.0)

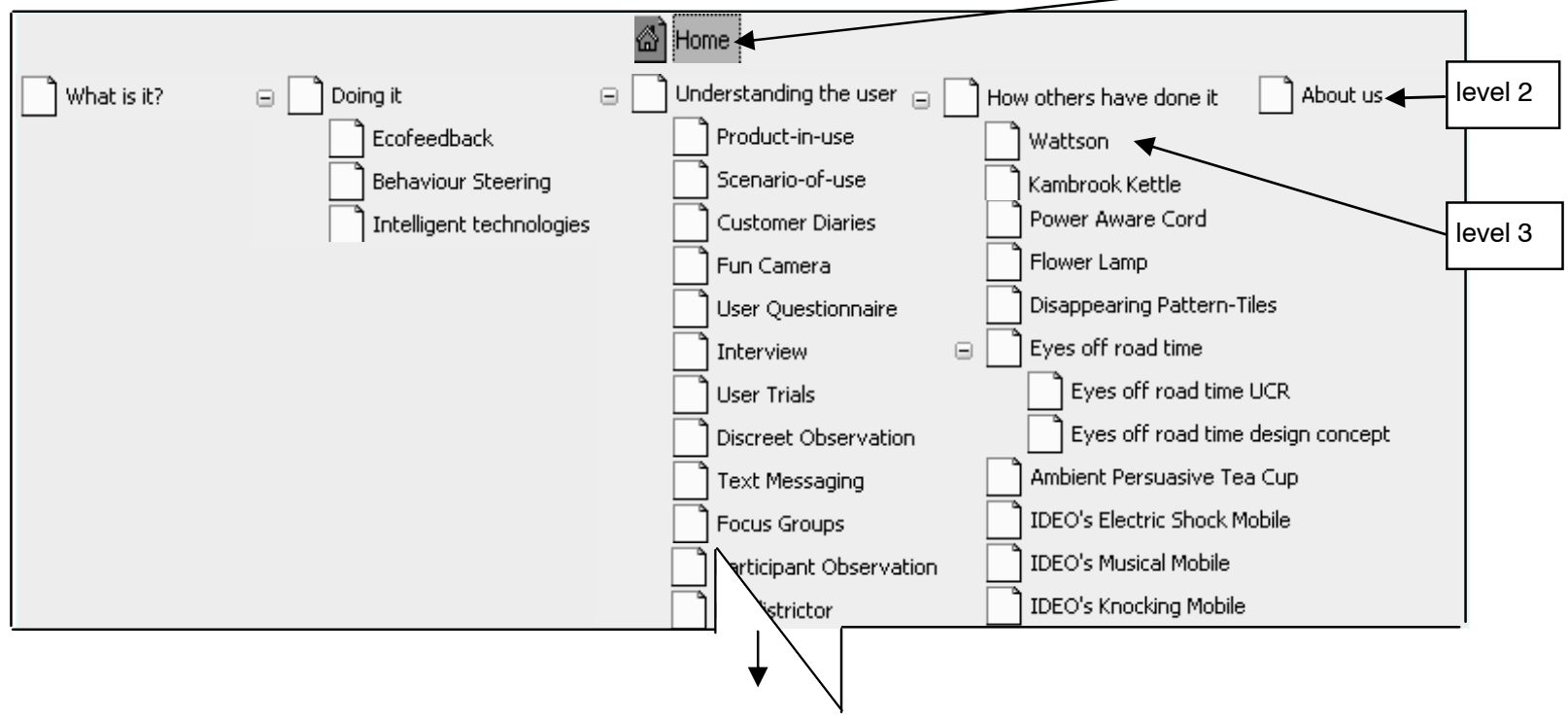


- $\quad$ specific case studies supported by evidence which validates the outcome

- scenarios depicting use to assist the designer in exploring product use in a specific context, including short films showing actual user behaviour.

The following paragraphs introduce the content contained in Version 1.0 of 'design-behaviour'.

\section{Welcome / homepage}

The welcome / homepage presented a brief introduction to the website and how to use it. The navigation menu to the left provided links to the five main sections.

\section{What is it?}

The 'what is it?' section gave a brief introduction to the concept of design for behavioural change, described the intended audience for the website and provided a rationale as to why those working in design and engineering professions should apply these approaches in practice. It also provided a central portal for relevant information and resources, including books, conference and journal papers, websites and blogs, as well as a list of researchers actively researching and publishing in related fields.

\section{Doing it}

The 'doing it' section listed three design for behavioural change approaches identified by Lilley (2007) (see Figure 4). Each approach was shown with a thumbnail image, title, brief description and link to the corresponding level 3 webpage which provided more detail and extra resources.
The information provided in the 'doing it' section was intended to be informative but not prescriptive. This section did not advocate the use of one approach in isolation, instead it encouraged the use of two or more approaches in tandem to emphasise that there is no single way to design for behavioural change and no hard and fast rules as to which approach to use.

\section{Understanding the user}

This section presented a range of user-centred research techniques drawn from the literature to assist practitioners in gathering user perceptions and observing 'real' behaviours in 'real' contexts. Each technique listed was linked to an individual webpage (see Figure 5) which provided a more detailed description, references to further information and examples of how the technique has been applied in practice. It was anticipated that this layout would enable users to select an applicable technique easily and quickly from the level 2 introductory webpage, then follow the link through to the level 3 webpage to acquire more information on their chosen technique.

\section{How others have done it}

The 'how others have done it' section aimed to provide the user with a broad range of case studies drawn from primary research (Lilley, 2007) which demonstrate how others have approached designing for behavioural change within the context of sustainable design (see Figure 6).
Figure 3.

Sample web page

illustrating key navigational aids

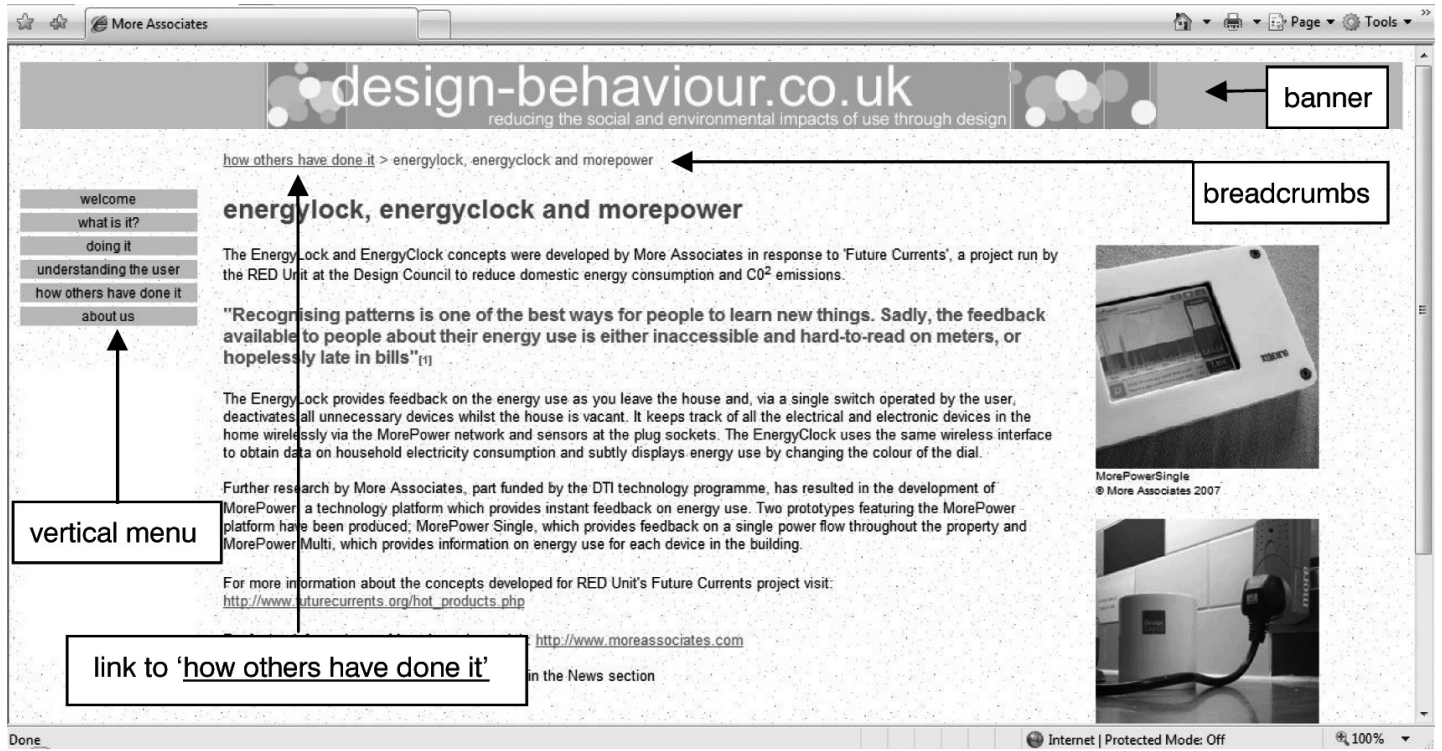


Figure 4.

'Doing it'

(level 2 web page)

Figure 5.

'Understanding the user'

(level 2 webpage)

\section{Figure 6.}

'How others

have done it' (level 2 webpage)

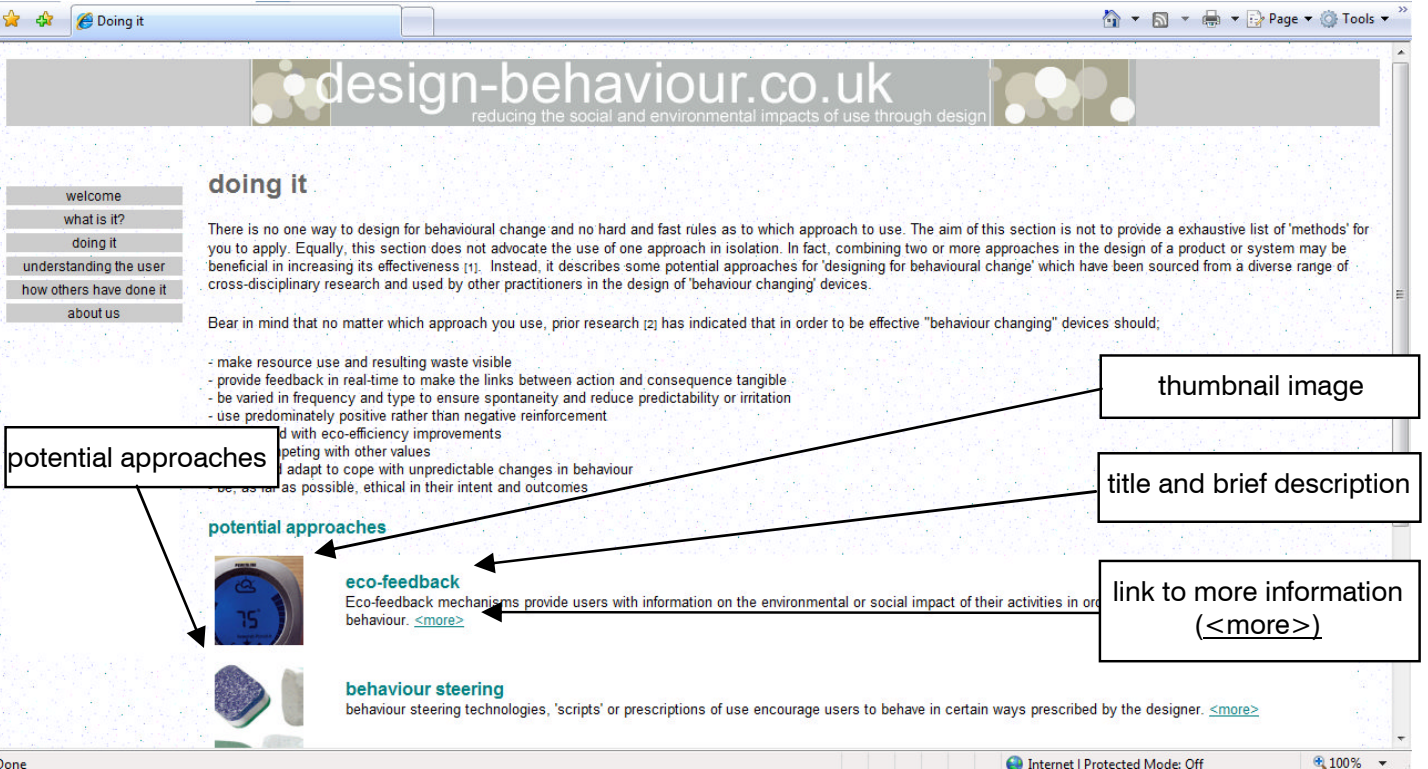

is the Understanding the user

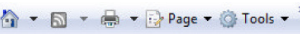

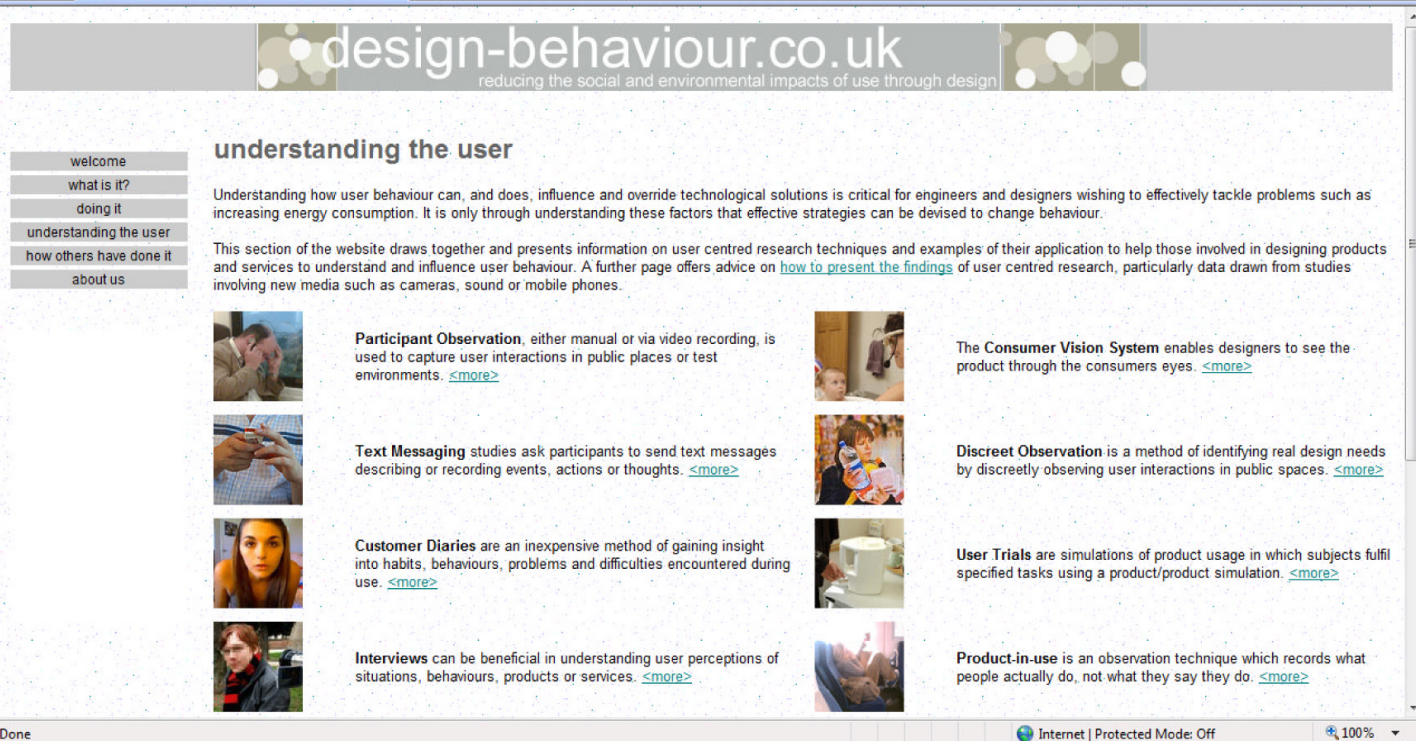

the How others have done it

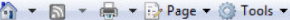

\section{design-behaviour.co.uk}

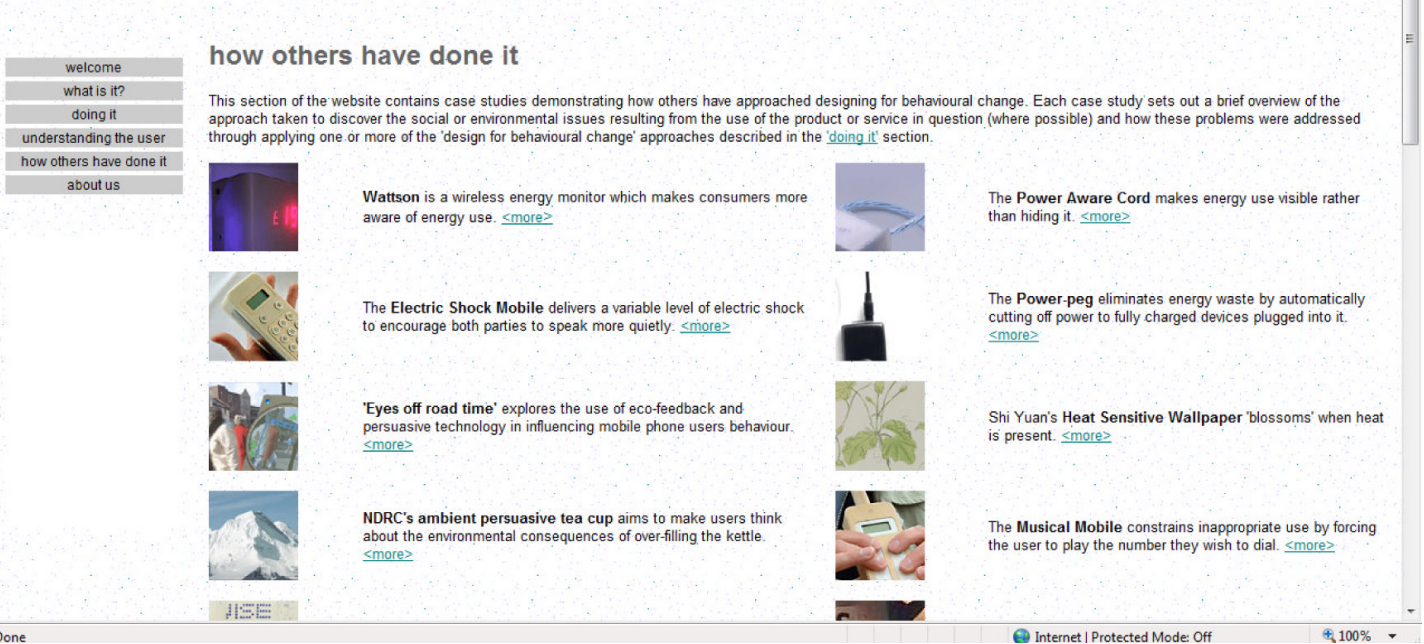


Each case study was linked to an individual webpage which set out a brief overview of the approach taken to identify the impacts resulting from use (where possible) and how these issues were addressed through applying one or more of the design for behavioural change approaches described in the 'doing it' section (see Figure 7).

\section{About us}

'About us' placed the 'design-behaviour' website within the context of Lilley's PhD research (2007) and charted the progression of its development. It outlined further areas of research to be carried out and provided a list of publications.

\section{Feedback}

Feedback on the suitability of the tool was sought using a questionnaire administered to a range of potential stakeholders via email. The majority of respondents (eight) considered themselves to hold an intermediate level of understanding of the subject, two felt they were intermediate to expert, one was an expert and one was a beginner. Findings from the survey are discussed below. To enable the authors to use direct quotes, whilst ensuring the anonymity of those who responded, each respondent was assigned a letter (e.g. 'k').

\section{Comments on content}

Feedback from the survey respondents widely complimented the informative content within the site and the useful links and references [e, $k, I]$ which connect this content to the broader picture.

\section{Who is it most useful for?}

All of the survey respondents who were beginners or intermediates felt that the website was most suited to their respective level of expertise. Some considered it to be suitable for all levels of expertise. The expert felt that it was most suitable for an intermediate level of expertise. This fits with the authors' opinion that the site would be most likely to support a beginner or intermediate level of familiarity and expertise in this field, rather than an expert who would more likely be engaged in research of their own.

\section{Most useful section}

When asked to rate the most useful section, the majority of survey respondents voted for 'how other have done it'. They all liked the wide range of good case study examples which help to "make it real" [a, d, f, k] and "aid understanding" [a, d] much better than theory alone [i]. The fact that they were visual and wide ranging was also recognised and commended. Feedback indicated that this section provided both education/awarenessraising and inspiration.

A few survey respondents preferred the 'doing it' pages, their general consensus being that the framework provided a clear layout. However, one survey respondent did not feel that this section was detailed enough and another felt that it was too detailed. This contradictory finding suggests that it would be worth investigating the suitability of this section in more detail. 'Understanding the user' was also recognised as very useful [j].
Figure 7.

'How others

have done it': 'power aware cord' (level 3 webpage)

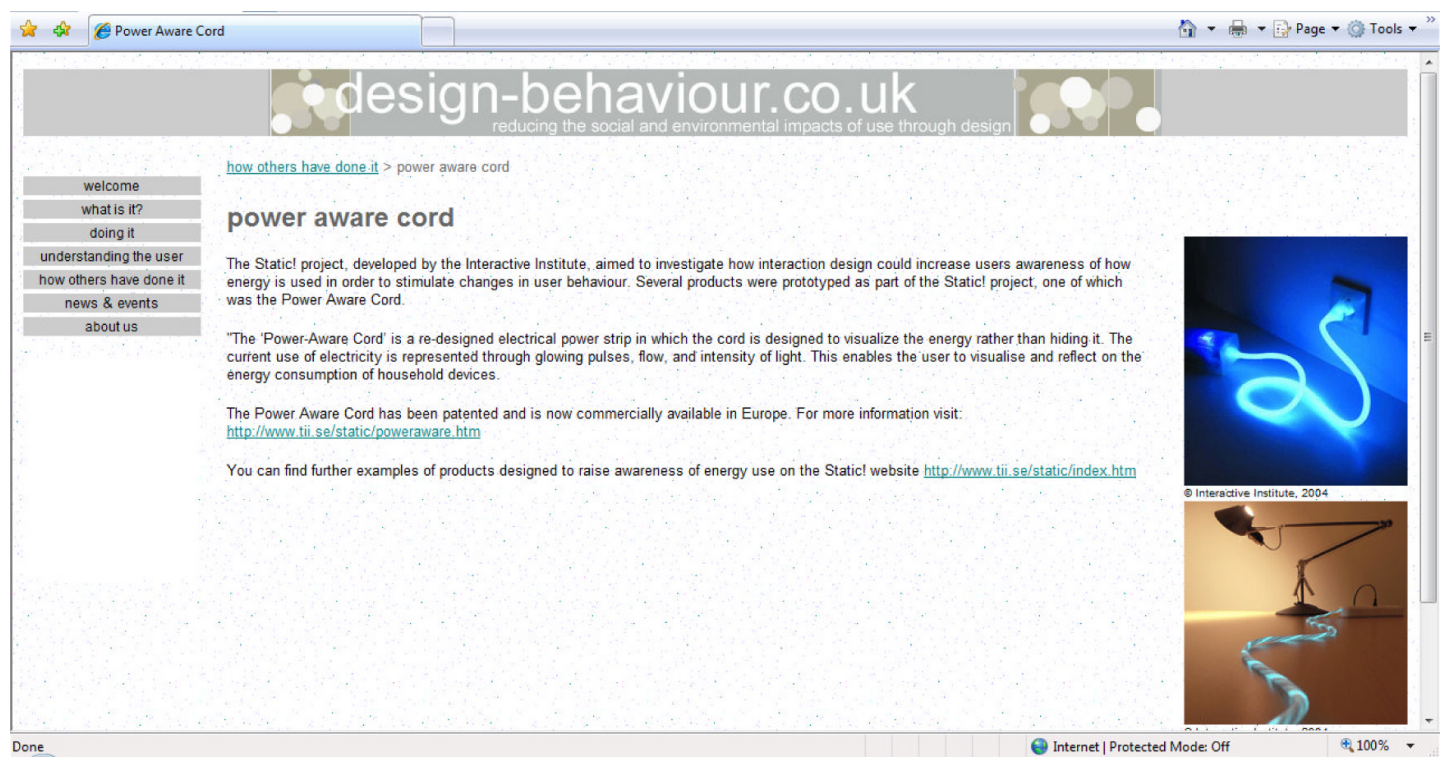




\section{Interfacing with the user (layout and navigation)}

All respondents stated that they found the site either easy or very easy to navigate around and technically the website appeared to be working well as no one had any problems viewing its content. The respondents also commented favourably on its simple layout and structure. One participant (a researcher) commented that they would value more cross linking between the sections [d]. This is undoubtedly an issue which could be investigated. All the respondents stated that they felt the language used was clear and easy to understand. One participant warned against "very occasionally [sounding]... slightly too academic" [e] and another commented on sections being "a bit text heavy" [a]. A review of these issues would help to streamline the resource and make it even more accessible.

\section{Usefulness of site}

All the survey respondents said that they would use the website as part of their design process. 'How others have done it' was seen as a key section to support this role. Sections 'what is it?, 'doing it' and 'understanding the user' all scored similarly and proved to be relatively popular second choices. One respondent said that he could use 'design-behaviour' to support his engineering teaching in two ways: firstly as inspiration for final year design projects and secondly as the basis of a group-working activity requiring students to apply one of the methodologies referred to by the website to a particular market segment or product area to generate design solutions. This comment suggests that specific teaching resources or guides for lecturers would be a useful addition to the resource.

\section{Further developments}

The feedback provided by respondents to the questionnaire enabled the authors to tailor and refine the website content to better reflect the audiences' needs. As a result several improvements were made and implemented in an updated version of 'design-behaviour' to increase the clarity of the information provided and forge stronger, more visible links between the theory ('doing it') and practice ('how others have done it') sections of the website.

The 'doing it' section of Version 1.0, though well received, presented a significant challenge in terms of how to structure and present the information. In Version 1.0 of the resource three design for behavioural change approaches, drawn from earlier research (Lilley, 2007), were presented, with links to more detailed information accessible through individual level 3 web pages (see Figures 2 and 4). As discussed in the feedback section some respondents considered the information provided in this section to be "too academic" or "text heavy". In Version 1.1, shown in Figure 8, these approaches have been refined and expanded upon to reflect current thinking (Bhamra et al., 2008b) and each approach is linked to relevant case studies in the "how others have done it' section to illustrate how it has been applied.

The information provided has been streamlined and a downloadable 'resource pack' added for those interested in reading more about the theory underpinning the approaches introduced. It is anticipated that this arrangement will cater more adequately for the primary audience's level of knowledge (indicated as 'beginner' or 'intermediate') whilst allowing those who wish to read more deeply on the subject to access additional materials.

\section{Discussion}

Providing an electronic resource to support the teaching of design for behavioural change has proven to be a very appropriate approach. It enables students to retrieve 'nuggets' of information (surface learning) or dig deeper to find more detailed information (deep learning) whilst also being very easy to update. From a teaching perspective, the 'layered' nature of the information provided enables case study examples to underpin the delivery of theory during a lecture whilst also providing a foundation for facilitating reflective questioning and discussion with students. This is particularly applicable in small group teaching where specific case studies contained in the resource can be used as a basis for group design activities and facilitated discussion. This resource also effectively supports independent study and project based learning.

To further improve interaction, the authors plan to integrate a moderated discussion forum into the resource to enable visitors to comment on the case studies presented in 'how others have done it'. It is anticipated that these comments will provide further stimulus for discussion and debate both within the classroom and in the wider design community. 
Figure 8.

Version 1.1

'doing it' web page

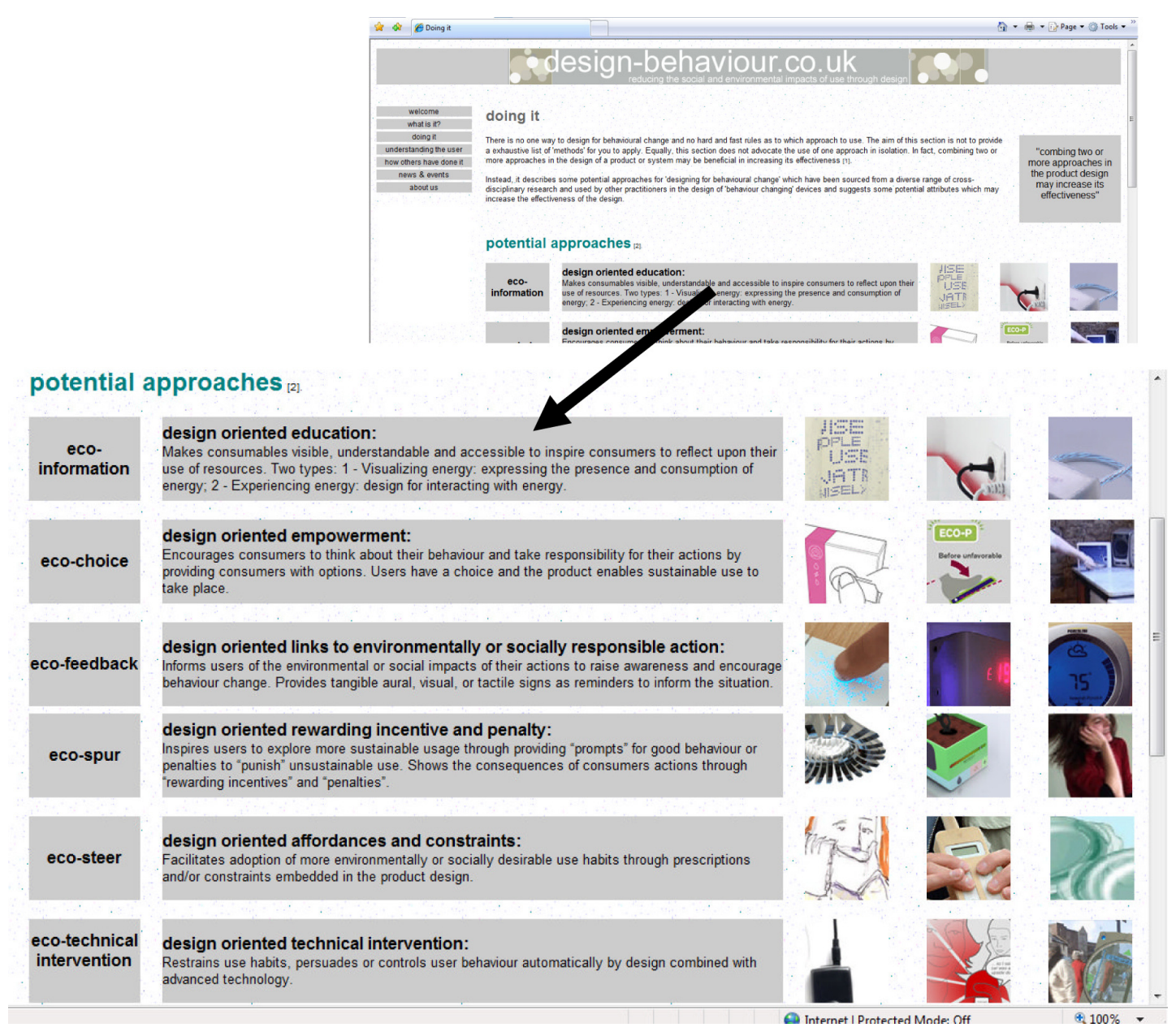

As with many student design projects, the outcomes from the activities reported in this paper were not taken through to a user testing phase and as such it was not possible to determine whether the resulting designs were successful in encouraging behaviour modification. However, it is evident that this approach is gaining recognition as a subject worthy of academic study (Lockton et al., 2008; Elias et al., 2008; Tang and Bhamra, 2008; Design and Behaviour, 2008) and, judging by the marked increase in 'behaviour changing' products on the market (DIY Kyoto, 2005; Product Creation Ltd, 2007; Nissan Global, 2008), it is increasingly of great interest to manufacturers as well.

\section{Conclusions}

Through this paper the authors have presented an iterative process of development and refinement which has supported the creation of a new resource for the teaching of design for behavioural change. Feedback on the resource at every stage has indicated a real need for this type of mechanism, with latter feedback also indicating that the approach which is being taken is not only relevant and interesting but also highly appropriate to the intended audience. The 'design-behaviour' resource has continued to evolve and is updated on a regular basis with new case studies, techniques and resources. It is currently used to support masters level project work in combination with studio based learning and the intention next is to integrate the updated resource into the teaching of second year sustainable design students at Loughborough University (outlined in the introduction) to support the design for sustainability strand of the module as part of a blended learning approach.

\section{Acknowledgements}

The authors would like thank the Higher Education Academy Engineering Subject Centre for the opportunity, funding and support which enabled 'design-behaviour' to be developed. We would also like to extend our thanks to all the individuals who trialled, tested and evaluated the website and those who contributed case studies. 


\section{References}

Akrich, M. (1992) The de-scription of technical objects. In Bijker, W. E. and Law, J. (eds.) Shaping technology: building society. Cambridge, Massachusetts: Massachusetts Institute of Technology (MIT), 205-224.

Bhamra, T.A., Lilley, D. and Tang, T. (2008a) Sustainable use: changing consumer behaviour through design. Sustainable innovation 08: future products, technologies and industries, 27-28 October 2008, Malmö, Sweden.

Bhamra, T.A., Lilley, D. and Tang, T. (2008b) Sustainable use: changing consumer behaviour through product design. Changing the change: design visions, proposals and tools, 10-12 July 2008, Turin, Italy.

Caroma (2008) Caroma Profile Toilet Suite, available online at http://www.caroma.com.au/products/ data/tsu/profile/main.html [accessed 20 March 2009[.

Darby, S. (2001) Making it obvious: designing feedback into energy consumption. 2nd International Conference on Energy Efficiency in Household Appliances and Lighting, Italian Association of Energy Economists/ EC-SAVE programme.

DEFRA (2002) Are you doing your bit? UK: DEFRA.

DEFRA, DfT and DCLG (2008) ACT ON CO , A cross-government initiative involving Department for Environment, Food and Rural Affairs (Defra), the Department for Transport (DfT) and the Department for Communities and Local Government (DCLG). Available online at http://campaigns.direct.gov.uk/actonco2/home.html [accessed 20 March 2009].

Design and Behaviour (2008) Google discussion group. Available online at http://groups.google.com/group/design-and-behaviour [accessed 20 March 2009].

Design Council (2005) Home Monitoring Display, RED Future Currents. Available online at http://www.futurecurrents.org/HM_home_monitoring.php [accessed 20 March 2009].

DeVries, M.J. (2006) Ethics and the complexity of technology: a design approach. Philosophia reformata, the international scientific journal of the Association for Reformational Philosophy, 71 (2), 118-131.

DIY Kyoto (2005) Wattson. Available online at www.diykyoto.com [accessed 20 March 2009].

Elias, E.W.A., Dekoninck, E.A. and Culley, S.J.C. (2008) Assessing user behaviour for changes in the design of energy using domestic products. IEEE International Symposium on Electronics and the Environment (ISEE), 19-22 May 2008, San Francisco, California, US.

Fogg, B.J. (2003) Persuasive technology: using computers to change what we think and do. San Fransisco: Morgan Kaufmann.

Garrison, D.R. and Kanuka, H. (2004) Blended learning: uncovering its transformative potential in higher education. The internet and higher education, 7 (2), 95-105.

Interactive Institute (2004) Static! Increasing energy awareness. Available online at http://www.tii.se/static/index.htm [accessed 20 March 2009].

Jelsma, J. and Knot, M. (2002) Designing environmentally efficient services: a 'script' approach. Journal of sustainable product design, 2 (3), 119-130.

Lewis, H., Gertsakis, J., Grant, T., Morelli, N. and Sweatman, A. (2001) Design + environment, Sheffield: Greenleaf.

Lilley, D. (2007) Designing for behavioural change: reducing the social impacts of product use through design. (Doctoral thesis, Department of Design and Technology, Loughborough University, Loughborough, UK.)

Lockton, D., Harrison, D. and Stanton, N. (2008) Making the user more efficient: design for sustainable behaviour. International journal of sustainable engineering, 1 (1), 3-8.

Lofthouse, V.A. (2001a) Facilitating ecodesign in an industrial design context: an exploratory study. Cranfield: Enterprise Integration.

Lofthouse, V.A. (2001b) Information/Inspiration. Available online at http://www.informationinspiration.org.uk [accessed 20 March 2009].

Lofthouse, V.A. (2004) Investigation into the role of core industrial designers in ecodesign projects. Design studies, 25 (2), 215-227.

Lofthouse, V.A. and Bhamra, T.A. (2004) Toolbox for sustainable design education. Available online at http://www.lboro.ac.uk/research/susdesign/LTSN/Index.htm [accessed 20 March 2009].

Lofthouse, V.A. and Bhamra, T.A. (2005) SortED. Loughborough: Loughborough University (CD $\mathrm{ROM})$. 
McCalley, L.T. (2006) From motivation and cognition theories to everyday applications and back again: the case of product-integrated information and feedback. Energy policy, 34 (2) 129-137. Nissan Global (2008) World first eco pedal helps reduce fuel consumption. Available online at http://www.nissan-global.com/EN/NEWS/2008/_STORY/080804-02-e.html [accessed March 2009].

Papanek, V. (1971) Design for the real world: human ecology and social change. New York: Pantheon Books.

Product Creation Ltd (2007) EcoKettle. Available online at http://www.ecokettle.com/ [accessed 20 March 2009].

Rodriguez, E. and Boks, C. (2005) How design of products affects user behaviour and vice versa: the environmental implications Environmentally conscious design and inverse manufacturing 2005, 12-14 December 2005, Tokyo, Japan.

Rogers, B.L. and Chaparro, B. (2003) Breadcrumb navigation: further investigation of usage. Available online at http://psychology.wichita.edu/surl/usabilitynews/52/breadcrumb.htm [accessed 20 March 2009].

Scott, F. (2004) Behaviour change - believing you can make a difference! BTCV, Global Action Plan and the Environment Council workshop, 20 July 2004, London.

Siegle, L. (2006) Your home may be hurting the planet. Guardian unlimited, Thursday 8 June 2006.

Tang, T. and Bhamra, T.A. (2008) Changing energy consumption behaviour through sustainable product design. International design conference - design 2008, 19-22 May 2008, Dubrovnik, Croatia.

Unilever (2000) Tablet detergents: towards a more sustainable future. Unilever HPC.

Van Hoff, D. (2003) The tyranny of the plug; kitchen machines that do not need to be plugged. Available online at http://www.vanhoffontwerpen.nl [accessed 20 March 2009].

\section{Contact details}

Dr Debra Lilley (BA, MRes, PhD), Research Associate, Department of Design and Technology, Loughborough University, UK. Tel: 07748652879 Email: d.lilley@lboro.ac.uk

Dr Vicky Lofthouse (BSc, PhD), Lecturer in Industrial Design, Department of Design and Technology, Loughborough University, UK. 